\title{
ATTRIBUTION STYLE AND INTERNAL STATE LEXICON: A COMPARISON BETWEEN INDIVIDUALS WITH INTELLECTUAL DISABILITY AND TYPICAL DEVELOPMENT
}

\author{
Marianna Alesi, Annamaria Pepi \\ University of Palermo, Italy \\ E-mail: marianna.alesi@unipa.it, annamaria.pepi@unipa.it
}

\begin{abstract}
Current theories of intellectual disabilities underlie an approach centred on a more complete description of the development, known as "the whole child approach", in which emphasis is placed on the reciprocal relationships between the cognitive and motivational dimensions which characterise development. In particular, subjects with intellectual disabilities, who have experienced repeated failures, may develop an attribution profile characterised by a bias towards primarily external causes. However the consideration of internal causes, such as effort and ability, requires the involvement of higher metacognitive and metalinguistic levels. Consequently, attribution to effort requires an awareness of one's own internal states. The aim of this study is to compare the attribution style and the knowledge of internal states words (physiological, emotional and cognitive) in adolescents with intellectual disability and typical development. Two groups consisting of 14 participants each were employed, an experimental group and a control group. The experimental group was composed by adolescents with intellectual disability. Participants in the control group were matched to the experimental Ss for mental age. All of the 24 participants were given an Attribution Test (Pepi and Alesi, 2001) and a Internal States Lexicon Test (Alesi and Pepi, 2005). The attribution test consisting of 14 items illustrating either everyday or school-related events in which the main character experiences either success or failure. The participants were asked to attribute the character's performance to one of five causes: ability; effort; help; luck; or task difficulty.

On the whole, individuals with intellectual disability tend to attribute mainly performance to external causes such as the ease of the task. Moreover the results show a significant relationship between attribution style and knowledge of internal states words. In summary this study provide support for the planning of multidimensional training programs aimed at internalize the attribution style in subjects with intellectual disability.
\end{abstract}

Key words: attribution style; intellectual disability; internal state lexicon; motivation.

\section{Introduction}

There is a growing body of evidence in the literature to demonstrate how a more complete description of the development in individuals with disability is needed. In particular "the whole child approach" (Ziegler, 1971, 1999) underlies the mutual relationships between the cognitive and motivational factors involved in the atypical development. Recent research focus on the pivotal role of the personality and the motivational dimensions which represent the nucleus around which all the other psychological and pedagogic processes capable of influencing the behavioural patterns of individuals with disability develop (Gilmore, 2011; Ziegler and Hodapp, 1991). A personal history characterised by a frequent lack of success, and thus by frustration, tends in the long term to cause individuals with 
disability to elaborate an idiosyncratic motivational profile which in turn decreases the quality of their performance on cognitive tasks. Also it stimulates the phenomenon of "deficit relative to academic and social/behaviour development" identifying the particular condition in which the low motivation level leads the disable to a deficit with respect to ability presumed on the basis of his mental age (Vianello and Lanfranchi, 2009, p.42). This could lead to the creation of a vicious circle, known as the Matthew effect. The mutual reinforcement of an emerging negative self-perception and refinement of cognitive skills, thereby encourages a maladaptive motivational profile and causes, in the most extreme cases, the development of learned helplessness (Stanovich, 1986; Switzky, 1999).

The above-mentioned idiosyncratic motivational profile is characterized by lower expectations of success connected with low levels of competence motivation and curiosity, low self-esteem, externally oriented attribution style, entity personal conceptions of intelligence, lower persistence (Bennet-Gates and Ziegler, 1999; Gilmore and Cuskelly, 2009).

However, this general outline of the motivational profile should be considered with a view to the specifics of the symptomological profiles which characterise different kinds of disability because individuals with disability should not all be grouped together on the basis of a single temperamental stereotype (Alesi and Pepi, 2008).

Although more research is needed, the attribution style represents a well documented motivation dimension in the current literature. Attributions to effort, ability, ease/difficulty of task, luck and help are factors which can influence an individual's thoughts, affective and behavioural state. Faced with obstacles, attributing performance to global, stable (such as lack of ability) or uncontrollable factors (such as lack of help) favours maladaptive behaviour. On the other hand, attributing performance to unstable or controllable factors (such as lack of effort) encourages adaptive behaviour (Weiner, 1985). In particular, individuals who have experienced repeated failure, such as those with disability, are more likely to develop an attribution bias. They are unlikely to manifest expectations of success and tend to attribute the outcomes of their performance to uncontrollable and stable causes, such as lack of ability. They often demonstrate an attribution over-extension, in that a primary cause, such as the need for help, may be used in various domains characterised by a marked non-contingency, precluding the consideration of other adaptive strategies, such as effort (Weisz, 1981, 1999). In this line, research evidences demonstrate how individuals with Down's syndrome compared with a control group with typical development attribute scant importance to effort and tend to over-estimate the external causes such as the help (Curti and Vianello, 1999; Pepi and Alesi, 2005).

Anyway the consideration of adaptive internal causes requires the involvement of higher metacognitive and metalinguistic levels. Consequently, attribution to effort needs the awareness of one's own internal states and an adequate level of internal state lexicon knowledge. The words that are used to refer to activities such as thinking, knowing, remembering and supposing, play an important role in the elaboration, comprehension, monitoring and transformation of mental internal states (Mitchell, 1996). The cognitions related words assume an important role in the development of the subject's metacognitive abilities since they stimulate and enable a deeper reflection and awareness (Olson \& Astington, 1995; Tardif \& Wellman, 2000).

According to cognitive and linguistic competences, the child's internal state lexicon emerges during the second year of life and has its most rapid development during the third year. It underlies this progressive order of understanding and production: physiological words, perceptual words, desire words, positive/negative emotion words and finally cognitive words (Pepi, 2000). These last ones include words that refer to cognitive states and their derivatives, such as think, know, believe, remember, forget, guess, pretend, understand...

According to the above-mentioned developmental model and the level of cognitive development reached, children and individuals with disability make reference to more superficial levels of elaboration of cognition related words. In other words they have difficulties with managing cognitive words but are often able to comprehend and to use physiological words, perceptual words, desire words (Pepi, 2000).

Cognitive state lexicon is an efficacy tool to investigate the causes of own outcomes of success or failure from the age of 3 years. Even if these two systems develop independently, they interact in order to allow the processing, the comprehension and the monitoring of the internal states (Mitchell, 1996; Pepi e Alesi, 2002; Symons, 2004). 
The internal attribution style requires the awareness of own mental states; subjects with poor internal state lexicon and low levels of mindreading tend to show low attributions to the effort (Abbeduto, Short-Meyerson, Benson and Dolish, 2004; Beeghly e Cicchetti, 1997). They prefer the external help to solve the new or ambigous tasks because they don't manage the role of internal causes, such as effort and ability, in determining the outcomes of events and performances (Wehmeyer e Palmer, 1997).

This account of internal state lexicon in attribution style development of individuals with disability is speculative. No study has openly investigated the relationship between these competences. In view of the above, the first aim of our study is to compare the attribution style of subjects with intellectual disability in situations of success or failure, with reference to school events versus everyday life with that of children of the same mental age.

A further aim of the study is to investigate the relationship between the attribution style and the knowledge of internal states lexicon (physiological, emotional and cognitive words) in subjects with intellectual disability and typical development.

\section{Methodology of Research}

\section{Sample of Research}

The sample consisted of 28 participants $^{1}$, equally distributed into two groups. The experimental group consisted of 14 adolescents with intellectual disability. The control group included 14 children matched to the experimental group for mental age and gender. To be more precise, the average chronological age of the subjects in the experimental group was 11.7, ranging from 8.7 to 14.8 , with an average mental age of 5.47 ranging from 5.02 to 7.08 . The control group consisted of children with an average chronological age of 5.6 (range $5-6.3$ ) and an average mental age of 5.2 (range $4.01-7.4$ ).

\section{Instruments and Procedure}

At the beginning of the study the OL test (Vianello and Marin, 1997) was administered to the participants in the experimental group and in control group, in order to determine their mental age. The OL test consists of 18 items, subdivided into three areas of logical operations: ordering, numbering and classification. For each item, evaluation was binary, with a mark of 1 being attributed to each correct item, and 0 to incorrect items. The raw data thus obtained were then transformed into a measure of mental age (range $4-8$ ) on the basis of appropriate conversion tables. The OL test is particularly suitable in mental retardation because it evaluates the logical thinking development and seems to limit the influence of cultural, linguistic and visuo-spatial aspects. Moreover it presents a good validity: correlation between OL Test and Wechsler Intelligence Scale is .68, correlation between OL Test and Columbia Mental Maturity Scale is 0.78 . Its reliability is 0.87 (Lanfranchi, Cornoldi and Vianello, 2004).

The attribution style was investigated by an Attribution Test (Pepi and Alesi, 2001) in 14 units related to everyday and school life stories. Of these 14 units, 7 represented experiences of success and other 7 experiences of failure. The first 3 illustrated stories showed scenes from everyday life ( 1 . assembling a jigsaw puzzle; 2 . a sports race; 3 . shopping at a supermarket). The fourth story was about a secondary school activity (4. making a poster) and the final three involved school activities (5. a history class; 6 . reading a text; 7 . working out a maths problem). Each unit involved the presentation of 6 illustrations, the first introducing the topic and the rest of them representing 5 possible causes (effort, ability, luck, ease/difficulty of the task, help), with the situation and character's reactions being indicated graphically by facial expressions and body language as well as the presence of other figures and their relationship to the main character. The children were asked to choose one of the five causes. In each unit, the first illustration represented the test assigned to the character (for example,

1 Participants were only 28 because sample procedures were very long and difficult in order to have a good matching between the two groups. 
assemble a jigsaw puzzle). For example, in the success condition, an illustration was accompanied by the prompt "Andrea manages to assemble the entire puzzle correctly. How did he do it?" This Volume 2, 2012 was immediately followed by presentation of five illustrations showing the character attributing the successful outcome of the task to one of the possible causes: ability, effort, help, luck and ease of the task. On the other hand, in the failure condition, the prompt was "Andrea doesn't assemble the jigsaw puzzle. Why not?" Here too, five illustrations were offered, representing the character attributing his failure to perform the task to different causes, namely, lack of ability, lack of effort, lack of help, bad luck, or the difficulty of the task. The five possible attributions were presented in random order in both conditions and were read by the researcher. The order of presentation of the success and failure conditions was balanced. One point was assigned to the choice on each item. The reliability coefficient of test was $\alpha=0.46$.

Finally the Internal State Lexicon Test (Alesi and Pepi, 2005) was given to the participants; the test consisted of 2 stories that described two characters felt, thought or knew something. Each story semantically and syntactically simple, permitted the evaluation of the knowledge of physiological, emotional and cognitive words. Each story was subdivided into 12 sentences, 4 referring to physiological states (to be hungry / to be tired), 4 to emotional states (to be happy / to be sad) and 4 to cognitive states (to think or to know).

The task involved reading or listening to the stories, picking out the target verb appropriate to the meaning of the sentence from a list of three choices of verbs. Responses to all cognition related verbs were monitored throughout the study of the employed verbs by two independent researchers also studying these topics. Distractor verbs syntactically suit the contexts and were chosen with regard to the frequency of their use and their conceptual level.

The scoring parameters of the evaluation were 1 for the right choice of verb and 0 when a distractor verb was chosen. Possible range of scores was 0 to 24 . The reliability coefficient of test was $\alpha=0.45$.

The obtained data were analyzed by One-Way ANOVA and by Pearson correlations.

\section{Results of Research}

The first aim of this study was to compare the attribution style and the internal state lexicon of individuals with intellectual disability and children of the same mental age.

Statistically significant differences emerged in the analyse between the two groups in their attribution choices regarding the ease of the task $[\mathrm{F}(1,27)=16,852 ; \mathrm{p}=0.000]$ and the help $[\mathrm{F}(1,27)$ $=4,822 ; \mathrm{p}=0.037]$. From the comparison of averages on the Bonferroni test $(\mathrm{p}<0.05)$, it became apparent that the group of adolescents with intellectual disability made significantly higher attributions to ease of the task than the group of normal children of the same mental age. The opposite trend emerged from an analysis of attributions to help. Adolescents with intellectual disability made a significantly lower number of attributions to the cause of help than the normal children (Figure 1).

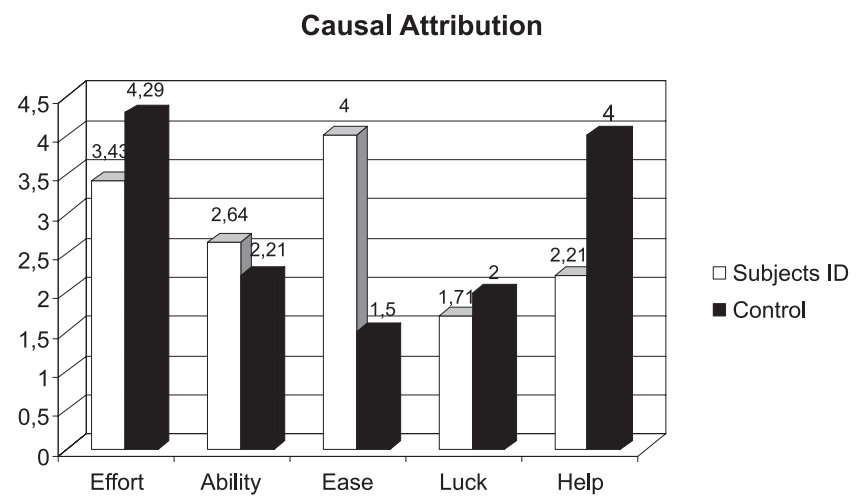

Figure 1: Attribution choices in subjects with intellectual disability and control group. 
With regard to the internal state lexicon, results revealed statistically significant differences between the groups in their comprehension of cognitive words $[\mathrm{F}(1,27)=13,252 ; \mathrm{p}=0.001]$ not in the categories of physiological or emotional references (Figure 2).

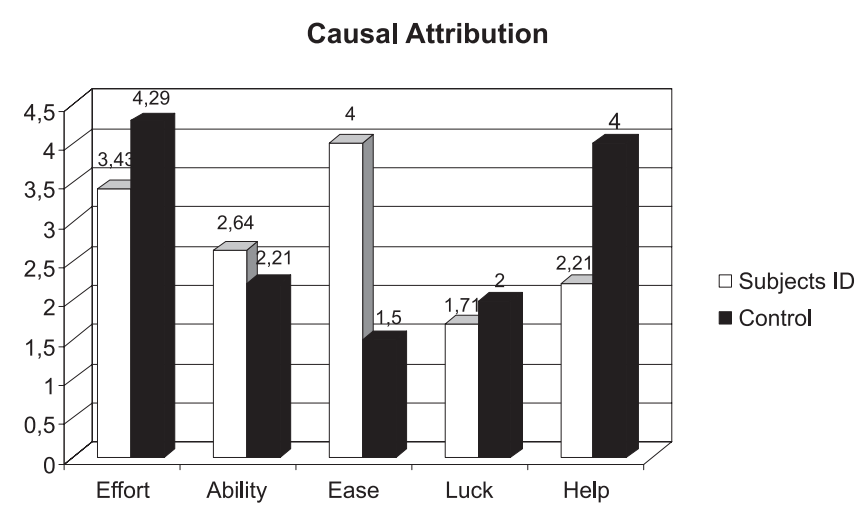

Figure 2: Comprehension of physiological, emotional and cognitive word in subjects with intellectual disability and control group.

Specifically the adolescents with intellectual disability have a significant lower comprehension of the verb "know" than the control group with normal development $[\mathrm{F}(1,27)=26,759 ; \mathrm{p}<0.001]$ (Figure 3).

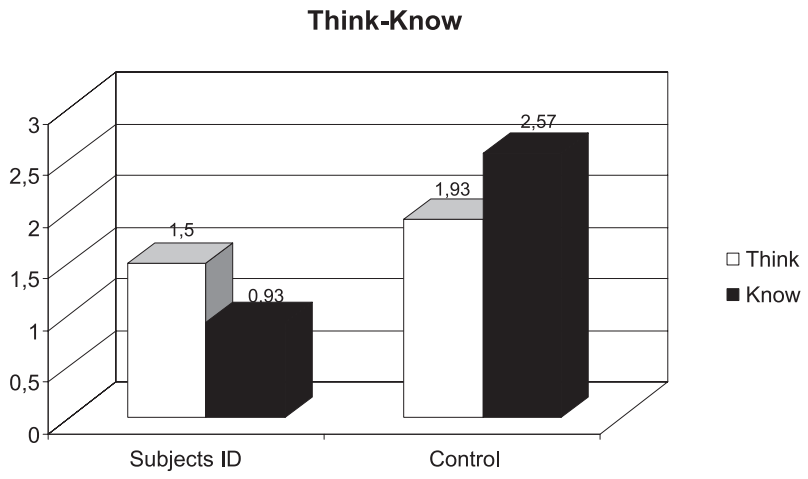

Figure 3: Comprehension of verbs Think and Know in subjects with intellectual disability and control group.

A further aim of the study was to investigate the relationship between the attribution style and the knowledge of internal states lexicon (physiological, emotional and cognitive words) in adolescents with intellectual disability and children with typical development matched for mental age.

In the group with intellectual disability a significant positive correlation can be observed between the comprehension of internal state lexicon and the causal attribution to the effort $(r=0.628$; $\mathrm{p}=0.016)$ and between the comprehension of cognitive state lexicon and the causal attribution to the effort $(\mathrm{r}=0.647 ; \mathrm{p}=0.012)$.

Similarly, in the group with typical development a significant positive correlation was found between the comprehension of internal state lexicon and the causal attribution to the effort $(\mathrm{r}=$ $0.583 ; p=0.029)$. Next, significant negative correlation was evidenced between the comprehension of internal state lexicon and the causal attribution to the help $(r=-0.686 ; p=0.007)$.

\section{Discussion}

The research reported here was designed to deepen the attribution style and the internal state lexicon in adolescents with intellectual disability compared and a control group matched for mental age. 
In general, adolescents with intellectual disability, compared with the other group, matched for mental age but not for chronological age, tend to prefer an attribution style oriented predominantly towards the choice of the ease of the task as their favoured cause of outcomes, in preference to the other four choices considered here, namely, effort, ability, luck and help.

Moreover the individuals with intellectual disability were found to chose less the cause of help, unlike the normal children, matched for mental age. This finding is not surprising in the light of the chronological age differences between the two groups. Probably the lower tendency of adolescents with intellectual disability (aged 11.7 years), when compared with children (aged 5.6 years), to attribute outcomes to help is supported by their life and school experiences. In particular, this tendency may well be influenced by various aspects of the social environment, such as teachers' style, which tend to promote the natural internalization of causal attribution and underlie the importance of the effort in school outcomes. On the contrary, children of control group, in line with development models concerning the attribution style, display a greater need for external guidance and develop an elevated level of dependence, which often manifests itself in the search for external support in attempts to solve new unfamiliar tasks. These children have less opportunities to acquire a norm of internality, and to compare their ideas with those of their peers and teachers, given their reduced school experience. Nevertheless, it is important to emphasize that this is a pilot study. The sample needs to be enlarged with another control group composed by subjects matched for chronological age to individuals with intellectual disability.

With regard to the internal state lexicon knowledge, adolescents with intellectual disability proved to have significantly lower competence in the cognitive verbs compared to those with typical development, therefore demonstrating a better knowledge of verb think. This finding is consistent with the theories of internal state lexicon development which postulate an hierarchical growth from physiological references to cognitive references knowledge. So the understanding and use cognitive words, which require deeper metalinguistic and metacognitive abilities, develop later and are impaired in the population with intellectual disabilities. ...It's worth noting that this ability recalls the phenomenon of "projection through capacities" underlied by Trofimova (1999) in the framework of psychosemantics. More specifically it refers to "...... when a person registers only those aspects of objects or situations that he can properly react to and deal with in their own behaviour" (p. 533). On the other hand a variety of studies document the key role of goals, learning or performance goals, in influencing self-perceptions and behaviours related to learning (Dweck, 1986; Pietsch, Walker and Chapman, 2003).

Moreover in the present study the causal attribution to the effort correlates with the internal state lexicon comprehension, particularly referred to cognitive words, in all both the groups. In the group of children with typical development the attribution to the help is negatively correlated to the knowledge of cognitive references. Together these findings are coherent with research in this field and provide support for the idea that the consideration of internal causes requires the involvement of higher metacognitive and metalinguistic levels, something which is especially difficult in intellectual disabilities (Ianes and Cramerotti, 2000; Sala, 2002). Given their difficulties with abstract thinking, they tend to have an impoverished lexicon, whose acquisition is delayed, for the description of internal states. Consequently, attribution to effort, which requires an awareness of one's own internal states, is less likely (Beeghly and Cicchetti, 1997). Moreover, they tend to be unrealistic in their causal attributions, because they don't fully understand the importance of effort and ability in determining the outcome of an event, of their own behaviour, or that of others, and therefore tend to favour external causes (Wehmeyer and Palmer, 1997).

\section{Conclusions}

In summary findings from the current study represent a step in studying the complex interactions between motivational and cognitive domains in individual with intellectual disability. In view of this findings, special attention should be paid to the development of an adaptive attribution style. According to this line of study, it's crucial to plan multi-faceted intervention programmes that take account both factors relating to motivation and underlying metalinguistic and metacognitive abilities. Domain-specific trainings alone are not enough to promote adaptive attribution styles emphasizing the internal causes such as the effort. Where necessary, it would be advisable to encourage internali- 
sation and the perception of effort as the cause of the own performance. A multi-faceted program should provide more effective support for the maintenance and generalisation of improvements by stimulating simultaneously abilities to understand and process the internal states.

Nevertheless, it is important to emphasize that this is a pilot study which employed a modest sample. Additional research with a larger sample is needed.

\section{References}

Abbeduto, L., Short-Meyerson, K., Benson, G., \& Dolish, J. (2004). Relationship between theory of mind and language ability in children and adolescents with intellectual disability. Journal of Disability Research, $48,150-159$.

Alesi, M., \& Pepi, A. (2005). Attribuzioni causali e lessico di stati fisiologici, emotivi e cognitivi nel ritardo mentale. Ciclo Evolutivo e Disabilità, VII, 1, 11-25.

Alesi, M. \& Pepi A. (2008). Il profilo motivazionale scolastico nello sviluppo tipico e atipico. Milano: Edizioni Unicopli.

Beeghly, M. \& Cicchetti, D. (1997). Talking about self and other: emergence of an internal state lexicon in young children with Down Syndrome. Development and Psychopathology, 9, 729-748.

Benneth-Gates, D. \& Ziegler, E. (1999). Expectancy of success in individuals with mental Retardation. In E. Ziegler \& D. Bennet-Gates (Eds) Personality in individuals with mental retardation, (Cambridge, Cambridge University Press).

Curti, T. \& Vianello, R. (1999). Stili attributivi in soggetti con sindrome di Down. In R. Vianello \& C. Cornoldi (Eds) Intelligenze multiple in una società multi cultura. Bergamo: Edizioni Junior, 112-131.

Dweck C. S. (1986). Motivational Processes Affecting Learning. American Psychologist, 41, 10, pp. 10401048.

Ianes, D., \& Cramerotti, S. (2000). Interventi metacognitivi nel ritardo mentale. Abilitazione e Riabilitazione, $I X, 2,19-33$.

Lanfranchi, S., Cornoldi, C., \& Vianello, R. (2004). Verbal and visuo-spatial working memory deficits in children with Down Sindrome. American Journal on Mental Retardation, 109, 6, 456-466.

Mitchell, P. (1996). Acquiring a conception of mind. Philadelphia: Psychology Press.

Olson, D. R., \& Astington, J.W. (1995). Pensare il pensiero. In O. Liverta Sempio, \& A. Marchetti Il pensiero dell'altro, Milano: Raffaello Cortina Editore.

Pepi, A., \& Alesi, M. (2002). Sviluppo del lessico cognitivo in bambini di età scolare. Ricerche di Psicologia, $3,57-74$.

Pepi, A. (2000). Lo sviluppo del lessico di stati cognitivi. Roma: Carlo Amore.

Pepi, A., \& Alesi, M. (2001). Stile attributivo e disabilità di lettura: proposta di un training. Ciclo Evolutivo e Disabilità, 4, 2, 241-253.

Pepi, A., \& Alesi, M. (2005). Attribution style in adolescents with Down's syndrome. European Journal of Special Needs Education, 20, 4, 341-353.

Pietsch, J., Walker, R., \& Chapman, E. (2003). The relationship among self-concept, self efficacy and performance in mathematics during secondary school. Journal of Educational Psychology, 95 (3), 589-603.

Sala, R. (2002). Una proposta di training specifico sugli stili attributivi nel ritardo mentale. A e R-Abilitazione e Riabilitazione, 66-84.

Symons, D. K. (2004). Mental state discourse, theory of mind and the internalization of self other understanding. Developmental Review, 24, 159-188.

Switzky, H. N. (1999) Intrinsic motivation and motivational self-system processes in persons with mental retardation: a theory of motivational orientation, in E. Ziegler \& D. Bennet-Gates (Eds) Personality in individuals with mental retardation Cambridge: Cambridge University Press, 37-60.

Tardif, R., \& Wellman, H.M. (2000). Acquisition of mental state language in mandarin and cantonese-speaking children. Developmental Psychology, 36, 1, 25-43.

Trofimova, I. (1999). How people of different age, sex and temperament estimate the world. Psychological Reports, 85, 533-552. 
Vianello, R., \& Lanfranchi, S. (2009). Genetic syndromes causing mental retardation: deficit surplus in school performance and social adaptability compared to cognitive capacity. Life Span and Disability, 12 (1), 41-52.

Vianello, R., \& Marin, M. L. (1997). O.L.C. Dal pensiero intuitivo al pensiero operatorio concreto: prove per la valutazione del livello di sviluppo. Bergamo: Junior.

Wehmeyer, M. L., \& Palmer, S. B. (1997). Perceptions of control of students with and without cognitive disabilities. Psychological Reports, 81, 195-206.

Weiner, B. (1985). An attributional theory of achievement motivation and emotion. Psychological Review, 92, 548-573.

Weisz, J. R. (1999). Cognitive performance and learned helpelessness in mentally retarded persons. In E. Ziegler, \& D. Bennet-Gates (Eds) Personality in individuals with mental retardation. Cambridge: Cambridge University Press, 37-60.

Ziegler, E. (1971). The retarded child as a whole person. In H. E. Adams \& W.K. Boardmna (Eds) Advances in Experimental Child Psychology, Vol. 1, New York: Pergamon.

Ziegler, E. (1999). The individual with mental retardation as a whole person. In E. Ziegler \& D. Bennet-Gates (Eds) Personality in individuals with mental retardation, Cambridge: Cambridge University Press, 23-36.

Ziegler, E. \& Hodapp, R.M. (1991). Behavioral functioning in individuals with mental Retardation. Annual Review of Psychology, 42, 29-50.

Advised by Aleksandr Lobanov, Belarusian State Pedagogical University, Republic of Belarus

Received: March 01, 2012

Accepted: March 26, 2012

\begin{tabular}{ll}
\hline Marianna Alesi & Ph.D, Assistant Professor, Department of Psychology, University of Palermo, V.le delle Scienze, \\
& Edificio 15,90128 Palermo, Italy. \\
& E-mail: marianna.alesi@unipa.it \\
& Website: http:///portale.unipa.it \\
\hline \multirow{2}{*}{ Annamaria Pepi } & Full Professor, Department of Psychology, University of Palermo, V.le delle Scienze, Edificio 15, \\
& 90128 Palermo, Italy. \\
& E-mail: annamaria.pepi@unipa.it \\
\hline
\end{tabular}

